\title{
MENINGKATKAN LITERASI IPA MELALUI INOVASI MODEL PEMBELAJARAN JENG KELIN GALLAW UNTUK SISWA SMP
}

\section{IMPROVING STUDENT'S SCIENTIFIC LITERACY THROUGH JENG KELIN GALLAW AS INOVATION LEARNING MODEL FOR MIDDLE STUDENT}

\author{
Anis Prasetiyaningsih \\ SMP Negeri 3 Jember \\ Email: anisprasetiyaollien@gmail.com
}

diterima : 20 Januari 201; dipublikasi : 30 Maret 2019

DOI: http://dx.doi.org/10.32528/bioma.v4i1.2648

\begin{abstract}
ABSTRAK
SMPN 3 Jember telah menerapkan kurikulum 2013 terintegrasi dengan literasi dan PPK melalui penerapan model pembelajaran yang sesuai dengan pendekatan saintifik. Penelitian ini menggunakan 3 indikator pada aspek kompetensi PISA 2015 yaitu 1)kemampuan menjelaskan fenomena ilmiah; 2)mengevaluasi dan merancang penelitian ilmiah; 3)menginterpretasi data dan bukti ilmiah. Tujuan Penelitian Tindakan Kelas ini untuk meningkatkan kemampuan literasi IPA.melalui inovasi model pembelajaran Jeng Kelin Gallaw pada siswa kelas VIII-A di SMP 3 Jember. Desain PTK Kemmis and McTaggrart dan dilakukan sebanyak 2 siklus. Indikator pencapaian keberhasilan yang digunakan adalah ada peningkatan kemampuan literasi IPA siswa pada aspek kompetensi menggunakan instrumen soal tes tulis dengan 3 indikator aspek kompetensi. Hasil ini menunjukkan bahwa inovasi model pembelajaran Jeng Kelin Gallaw dapat meningkatkan kemampuan literasi IPA siswa kelas VIII-A.
\end{abstract}

Kata Kunci: Literasi IPA, Inovasi Model pembelajaran, Jeng Kelin Gallaw

\begin{abstract}
SMP 3 Jember have applied kurikulum 2013 integrated with literacy and character education through the implementation of learning model which appropiate to scientific approach. This research used three aspect of PISA 2015 in the aspect of competency they are 1) explaining scientific phenomena; 2) using scientific evidence; 3 ) identifying scientific issues This Classroom Action Research (CAR) have purposed for improving student scientific literacy in competency aspect through inovation learning model called as Jeng Kelin Gallaw for the students in grade VIII-A. Design in this research was used Classroom Action Research design. Kemmis and McTaggrart which done in 2 cycles and the result of study showed that inovation learning model of Jeng Kelin Gallaw can improve student's literacy
\end{abstract}

Keywords: Scientific Literacy, Learning Model's Inovation, Jeng Kelin Gallaw 


\section{PENDAHULUAN}

Keterampilan 4C pebelajar abad 21 dalam framework for $21^{\text {st }}$ century Learning yaitu kreativitas, berpikir kritis, memecahkan masalah, berkomunikasi dan berkolaborasi hendaknya diintegrasikan dalam merencanakan pembelajaran untuk keberhasilan siswa di masa akan datang $(P 21,2012: 7)$. Literasi IPA adalah sebuah untuk melibatkan siswa dengan isu-isu terkait sains menggunakan pengetahuan sains sebagai seorang warganegara yang reflektif (OECD, 2016-13). PISA 2015 mendefinisikan literasi IPA kedalam empat aspek 1) context yaitu konteks personal, global dan lokal; 2) knowledge yaitu aspek pengetahuan, konten, pengetahuan procedural dan pengetahuan epistemik; 3) competencies meliputi kemampuan untuk menjelaskan fenomena ilmiah, kemampuan merancang dan menevaluasi penelitian ilmiah, kemampuan menginterpretasi data dan bukti ilmiah; 4) attitudes meliputi sikap seseorang terhadap sains ditandai dengan ketertarikan, perhatian dan respon mereka dalam sains dan teknologi serta isu yang berkaitan (OECD, 2016-23).

Permasalahan terjadi ketika guru melatihkan kemampuan literasi IPA siswa saat menerapkan model Project Based Learning di kelas VIII-A materi indera pendengaran dan sistem SONAR. Kajian Model PjBL secara teori dan empiris banyak dilakukan oleh para ahli dan praktisi, penerapannya mampu meningkatkan kemampuan siswa berpikir kritis, memecahkan masalah, berkolaborasi, dan meningkatkan hasil belajar siswa (Sumarni, 2013:480). Siswa yang mendapatkan tugas proyek memiliki pengalaman langsung dan pengetahuan bermakna yang bermanfaat bagi kehidupannya (Susilowati, dkk., 2013).

Kenyataan yang penulis hadapi ketika menerapkan model $P j B L$, hasil tes tulis dengan menggunakan indikator tes kemampuan literasi IPA menunjukkan siswa di kelas VIII-A tidak tuntas klasikal dengan rata nilai 72,5. Hasil tersebut jauh dari KKM di SMP 3 Jember yaitu 80. Skor paling rendah pada indikator soal aspek kompetensi literasi IPA. Kemampuan literasi IPA siswa dalam merancang dan mengevaluasi penelitian ilmiah, kemampuan menginterpretasi data dan bukti ilmiah masih dibawah KKM. Proyek yang diberikan guru ternyata juga belum 100\% mampu memotivasi siswa terlibat aktif dalam kerja kelompok. Pembelajaran yang telah dilakukan tidak memberikan pemahaman yang merata pada seluruh siswa dalam kelompok. Pembelajaran menjadi kurang memberikan makna bagi siswa, terbukti siswa masih 
banyak mengalami kesulitan dalam menghubungkan antara fenomena ilmiah dengan konsep yang telah pelajari. Guru juga terlambat mengetahui kendala siswa selama pembelajaran sehingga tidak segera membantu kesulitan yang dialami siswa. Hasil analisis terhadap catatan di buku tulis siswa, catatan siswa terbatas pada apa yang ditulis guru di papan tulis dan telah ditampilkan pada slide power point.

Guru selama melaksanakan $P j B L$ hanya terfokus pada hasil pencapaian proyek yang dikerjakan siswa dalam kelompok, hal ini menyebabkan guru tidak mengetahui kendala siswa secara individu. Masalah yang terjadi menjadi tantangan guru untuk segera menemukan solusi yang tepat sebagai upaya perbaikan di pembelajaran selanjutnya pada siswa kelas VIII-A untuk mengatasi kendala yang dihadapi utamanya dalam meningkatkan kemampuan literasi IPA. Kemampuan literasi IPA harus dilatihkan dengan strategi yang memberi siswa kemudahan memproses informasi selama pembelajaran. Strategi dimana siswa tidak sekedar mampu menyelesaikan proyek tepat waktu tetapi juga memahami apa yang telah, sedang dan akan mereka lakukan. Strategi yang memberi kesempatan siswa menyampaikan kendala yang dihadapi sebagai feedback, sehingga guru sebagai fasilitator dalam pembelajaran dapat dengan segera membantu kendala yang dialami dan menjadi refleksi guru di pembelajaran selanjutnya.

Penerapan $P j B L$ perlu dikolaborasi dengan strategi dan metode yang sesuai dengan kondisi siswa kelas VIII-A untuk mencapai tujuan pembelajaran. Kolaborasi menulis jurnal belajar mengasah kemampuan siswa dalam menulis, mengungkapkan dan melaporkan apa yang telah mereka lihat, lakukan, temukan baik secara individu ataupun kelompok (National Research Coucil, 2012). Jurnal belajar yang bersifat reflektif dapat melibatkan kemampuan berpikir siswa dalam aktivitas brainstorming, reflection, questioning, prediction serta mampu mengekspresikan ketertarikan dan rasa ingin tahu mereka tentang dunia disekitar dan menemukan ide baru (Al Rawahi \& ALBalushi, 2015:368). Jurnal belajar reflektif menggunakan strategi KELIN berupa kolom pada jurnal belajar siswa secara berurutan yaitu Know, Explore, Learned, In daily life dan Note. Siswa menulis apa yang telah diketahui tentang topik yang akan dibahas (know); menstimulasi siswa merumuskan pertanyaan seputar topik yang ingin dieksplorasi (explore), menulis poin penting yang telah diperoleh setelah pembelajaran (learned). Siswa dengan bimbingan guru menemukan aplikasi topik di kehidupan 
sehari-hari (In daily life) bertujuan agar siswa dapat menghubungkan fenomena ilmiah dengan konsep yang diapahami. Note sebagai kolom refleksi siswa dan feedback siswa terhadap guru dari pembelajaran yang telah dilakukan.

Gallery merupakan bagian dari proyek sederhana menggunakan kertas plano sebagai dari hasil kolaborasi pemikiran tentang topik yang sebelumnya telah dibagi oleh guru. Gallery dipersiapkan untuk kunjungan oleh kelompok lain ke setiap Gallery untuk dapat saling memberi masukan, pujian dari karya yang dibuat. Metode ini berawal dari ide dasar metode Gallery Walk, metode yang mampu memberi kesempatan siswa berdialog interaktif sesama teman dan guru dan beinteraksi pada sumber belajar secara langsung. Metode yang mampu untuk menilai dan mengingat apa yang telah dipelajari oleh siswa selama pembelajaran (Velazquez, et al., 2007:28).

Sebuah research study yang dilakukan oleh Davis,W (2015) tentang penggunaan sticky note dalam meningkatkan literasi metakognitif disebutkan bahwa:

"Providing students with choice about what to write on their sticky notes is a motivational tool. When many thoughts are read, ideas, and connections form during the process"

Sehingga pada pelaksanaan Gallery walk ini penulis kembangkan menjadi Gallery attach walk, yaitu dengan melakukan attachment (penyematan) menggunakan alat sticky note. Urgensi penelitian tindakan kelas penerapan model pembelajaran proyek JENG KELIN GALLAW pada siswa kelas VIII-A di SMP Negeri 3 Jember bertujuan utama agar siswa mengalami peningkatan kemampuan literasi IPA aspek kompetensi yaitu menjelaskan fenomena ilmiah, mengevaluasi dan merancang penelitian ilmiah serta menginterpretasikan data dan bukti ilmiah.

JENG KELIN GALLAW adalah inovasi model pembelajaran hasil kolaborasi model $P j B L$ dengan penugasan proyek berupa gallery attach walk yang ditampilkan oleh kelompok yang merupakan kolaborasi pemikiran yang tertulis pada jurnal dalam format kolom KELIN.

Gallery Walk atau pameran berjalan merupakan metode presentasi agar siswa dapat bekerjasama secara aktif bersama kelompok menampilkan hasil kolaborasi anatar anggota kelompok. Gallery walk dapat digunakan untuk menilai dan mengingat apa yang telah dipelajari oleh siswa selama pembelajaran. Setiap kelompok nantinya akan mengamati hasil kelompok lain dengan cara berjalan dari galeri kelompok satu ke 
kelompok yang lainnya (Velazquez, et al., 2007:28). Gallery walk sebuah metode digunakan sebagai alternatif bagi guru dalam membelajarkan siswa aktif. Kajian empiris penulis pada beberapa penerapan Gallery Walk dalam pembelajaran memberikan hasil positif dalam pencapaian hasil belajar, peningkatan sikap saling menghargai, meningkatkan partisipasi siswa (aktivitas siswa) dalam kelompok belajar, aktivitas belajar yang meningkat, meningkatkan kedisiplinan, mendapat tanggapan positif dari siswa pada guru yang telah menerapkan Gallery Walk dalam pembelajaran, menumbuhkan rasa ingin tahu (Arif, 2013; Sari, 2014; Sukma dkk, 2016). Galery walk mampu melatih keterampilan siswa dalam menyajikan karya (Prasetiyaningsih, 2014).

Penerapan Gallery Walk pernah diterapkan oleh penulis dan hasilnya keterampilan siswa dalam menyajikan karya menjadi lebih baik (Prasetiyaningsih, 2014). Inovasi pembelajaran ini menjadi pembaruan GalleryAttach-Walk (GALLAW) dengan tambahan tahapan attach (melampirkan) refleksi dan feedback dari siswa kepada proyek kelompok lain. Sehingga siswa mendapatkan penilaian yang objektif dari sesama teman, saling memberi masukan dan saling menghargai hasil karya satu sama lain.

GALLAW (Gallery Attach Walk) adalah proyek yang dikerjakan siswa dalam kelompok kerja dengan memiliki ciri tahapan sebagai berikut.

1) GALLAW adalah metode penyajian proyek yang dikerjakan siswa dalam kelompok.

2) Tema tugas ditentukan guru sesuai dengan topik dan tujuan pembelajaran didiskusikan.

3) GALLAW dikerjakan setelah siswa melalui serangkaian aktivitas belajar mengajar dengan memanfaatkan tabel KELIN masing-masing anggota kelompok.

Tahapan attach pada metode GALLAW mengajarkan kepada siswa untuk dapat terbuka dalam memberikan penghargaan kepada teman atau kelompok yang memiliki karya yang menurut siswa baik dan menarik, siswa belajar mengungkapkan kritik dan komentar hasil pengamatan galeri dengan sopan, siswa belajar terbuka menerima masukan teman, melatih kemampuan bertanya.

\section{JENG KELIN sebagai Implementasi Jurnal Belajar}

Penulisan jurnal belajar dapat membantu siswa dalam belajar dan mencapai tujuan pembelajaran jika diberikan arahan sesuai instruksi guru (Wati \& Susilo, 
2016:860). Penulisan jurnal belajar melatih siswa untuk memiliki keterampilan menulis yang baik dalam pembelajaran karena terbisa menyusun kalimat sendiri, sehingga mempertajam interpretasi dan argumen mereka pada hasil pengamatan dan penemuan yang telah mereka lakukan dalam pembelajaran. Jurnal belajar meningkatkan kemampuan dan pemahaman siswa melalui inkuiri, siswa mendapatkan pengalaman untuk mengidentifikasi dan merekam apa yang telah ereka pelajari di dalam pembelajaran di kelas. (Towndrown, et al., 2008:282). Jurnal reflektif siswa memberi siswa banyak kesempatan melatih mencatat dengan baik apa yang telah dilakukan, melatih menganalisis pertanyaan yang ada dengan jawaban berdasarkan pengalaman belajar mereka, jurnal juga bermanfaat bagi guru sebagai salah satu sumber informasi dalam mengetahui sejauh mana pemahaman siswa dan dapat langsung mengetahui kesalahan konsep yang mungkin dialami siswa dapat segera teratasi (Towndrown, et al., 2008:283). Hasil penelitian menunjukkan bahwa jurnal belajar reflektif bermanfaat sebagai regulasi diri, siswa menuliskan refleksi dari hasil eksperimen, observasi, mengungkapkan perasaannya dan guru langsung memberikan feedback dari jurnal siswa (Al-Rawahi \& Al-Balushi, 2015). Memfasilitasi siswa dalam membantu memproses informasi dan mengorganisasi keterampilan berpikir dengan kemampuan bertanya akan meningkat dan meningkatkan kemampuan berpikir siswa, kemampuan berpikir kritis siswa meningkat (Gusliani, 2014; Munawaroh dkk., 2015).

Strategi pemrosesan infromasi yang telah ada membantu siswa mengorganisasi cara berpikir sebagai bentuk strategi metakognitif (Zouhor, dkk., 2016). Penggunaan KELIN sebagai strategi pemrosesan infromasi bertujuan membantu siswa mengorganisasi informasi, membantu mereka belajar bagaimana belajar, mengaktifkan aktivitas recalling dan brainstoring (know), meningkatkan kemampuan dalam merumuskan pertanyaan (Explore), menuliskan kembali kegiatan dan konsep penting yang telah mereka lakukan (Learned), menemukan contoh dan aplikasi dari konsep yang dipelajari dengan fenomena ilmiah dalam kehidupan sehari-hari dan menuliskan refleksi pembelajaran (note).

JENG KELIN adalah jurnal belajar yang disusun dengan pengorganisasian proses berpikir yang variasi antara lain aktivitas brainstorming, reflection dan 
questioning. JENG KELIN dibuat siswa secara individu dalam buku tulis IPA dengan format tabel sebagai berikut.

Tabel.1 Format kolom JENG KELIN

\begin{tabular}{lllll}
\multicolumn{1}{c}{ Know } & \multicolumn{1}{c}{ Explore } & \multicolumn{1}{c}{ Learned } & \multicolumn{1}{c}{ In daily life } & \multicolumn{1}{c}{ Note } \\
\hline What di & What questions that & What have you & What are the & Write your \\
you Know & makes you want to & LEARNED in & application IN DAILY & NOTE about \\
about the & EXPLORE & today's science learning? & LIFE related the topic? & today's lesson! \\
topic? & more about the topic? & & & \\
\hline
\end{tabular}

Fungsi JENG KELIN bagi siswa, yaitu

1) membantu siswa dalam mengorganisasi informasi;

2) recalling pengetahuan yang telah dimilikinya;

3) membantu siswa dalam belajar bagaimana belajar (metakognitif);

4) siswa dapat melakuan refleksi dari pembelajaran hari itu;

5) siswa dapat meningkatkan kemampuannya meregulasi diri agar lebih baik;

\section{METODE}

Penelitian ini dengan metode kualitatif dengan desain PTK Kemmis and Mc Taggrart dengan tahapan perecanaan, pelaksanaan, pengamatan dan refleksi di tiap siklusnya. Penelitian tindakan kelas yang terdiri dari 2 siklus.

a. Tahap Perencanaan pembelajaran

Membuat RPP dengan melihat KI dan KD pada silabus IPA kelas VIII dan menyiapkan bahan ajar). Pada tahapan ini penulis menyusun RPP dengan memperhatikan setiap aktivitas berharga yang akan siswa lakukan, RPP pada Siklus ke-1 dan ke-2 masing masing terdapat 3 pertemuan (alokasi waktu $8 \mathrm{JP}$ ).

b. Pelaksanaan (menggunakan model JENG KELIN GALLAW)

Aplikasi praktis penerapan model proyek JENG KELIN GALLAW dalam pembelajaran IPA di kelas VIII-A seperti tabel.2 sebagai berikut.

Tabel.2 Sintaks Model Proyek JENG KELIN GALLAW

\begin{tabular}{lllll}
\hline \multicolumn{1}{c}{ SINTAKS } & \multicolumn{3}{c}{ PERAN GURU } & PERAN SISWA \\
\hline 1. Pembuatan dan & Memandu siswa untuk mengisi & kolom & Membuat tabel JENG KELIN \\
penulisan JENG & KELIN sesuai dengan urutan yaitu Know, & Menuliskan & kolom sesuai urutan tabel \\
KELIN & Explore, Learned, In daily lifes, Note & KELIN & \\
\hline
\end{tabular}




\begin{tabular}{|c|c|c|}
\hline SI & PERAN & ISWA \\
\hline $\begin{array}{l}\text { 2. Pengumpulan } \\
\text { JENG KELIN }\end{array}$ & $\begin{array}{l}\text { JENG KELIN dikumpulkan, dibaca, } \\
\text { dikomentari, dicatat guru sebagai feedback }\end{array}$ & $\begin{array}{l}\text { Memastikan telah mengisi KELIN sesuai } \\
\text { instruksi }\end{array}$ \\
\hline $\begin{array}{l}\text { 3. Persiapan } \\
\text { Proyek GALLAW }\end{array}$ & $\begin{array}{l}\text { Anggota kelompok GALLAW dibuat oleh } \\
\text { guru berikut topik yang akan dikerjakan } \\
\text { siswa bersama kelompok }\end{array}$ & $\begin{array}{l}\text { Menemukan satu rumusan masalah } \\
\text { penyajian proyek sesuai kesepakatan } \\
\text { kelompok }\end{array}$ \\
\hline $\begin{array}{l}\text { 4. Pembuatan } \\
\text { gallery }\end{array}$ & $\begin{array}{l}\text { Memandu siswa berkolaborasi dalam } \\
\text { kelompok dan Sebagai fasilitator }\end{array}$ & $\begin{array}{l}\text { Berkolaborasi } \\
\text { kelompok }\end{array}$ \\
\hline $\begin{array}{l}\text { 5. Pelaksanaan } \\
\text { Attach Walk }\end{array}$ & $\begin{array}{l}\text { Memastikan seluruh anggota dalam satu } \\
\text { kelompok telah tersebar ke sejumlah gallery } \\
\text {; memastikan setiap siswa telah memiliki } \\
\text { sticky note; memperingatkan waktu kegiatan }\end{array}$ & $\begin{array}{l}\text { Melaksanakan attach dan walk secara } \\
\text { tertib; menempel attach pada gallery } \\
\text { yang di kunjungi sebagai bentuk sikap } \\
\text { kritis dan terbuka namun tetap } \\
\text { berkarakter sopan }\end{array}$ \\
\hline 6. Evaluasi Proyek & $\begin{array}{l}\text { Sebagai fasilitator dalam evaluasi dan } \\
\text { refleksi proyek }\end{array}$ & $\begin{array}{l}\text { Membaca attach pengunjung gallery dan } \\
\text { evaluasi bersama }\end{array}$ \\
\hline
\end{tabular}

c. Pengamatan

Pengamatan dilakukan bersamaan dengan pelaksanaan kegiatan. Pengamatan dilakukan oleh guru sebagai peneliti dengan bantuan teman sejawat sebagai observer menggunakan alat bantu lembar observasi keterlaksanaan pembelajaran dalam hal ini kinerja guru dalam melaksanakan model pembelajaran JENG KELIN GALLAW dan juga lembar observasi aktivitas siswa dalam hal ini kinerja siswa selama pembelajaran.

d. Refleksi

Selama penelitian dilaksanakan, hasilnya dianalisis dan dikaji keberhasilan dan kegagalannya. Data yang diperoleh pada proses belajar mengajar apabila hasil analisis pada siklus I ada revisi dan kekurangan maka analisis direfleksikan untuk menentukan tindakan pada siklus 2 dalam rangka mencapai tujuan penelitian.

\section{HASIL DAN PEMBAHASAN}

\section{Hasil Siklus I}

Tes tulis literasi IPA kelas VIII-A berjumlah 4 soal dengan tiga indikator Literasi IPA pada PISA 2015, hasil yang diperoleh berdasarkan analisis tes Literasi IPA sebagai berikut.

1. Indikator pertama: fenomena ilmiah dengan rata-rata nilai 91,1 .

2. Indikator kedua: merancang dan mengevaluasi penelitian ilmiah rata-rata 78,6 ; 
3. Indikator keempat: menginterpretasi data dan bukti ilmiah dengan rata nilai 86,1

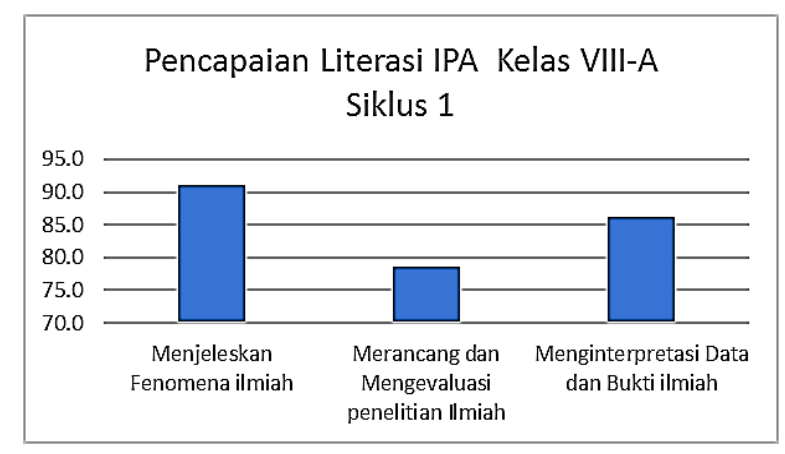

Gambar 1. Pencapaian Literasi IPA kelas VII I-A Siklus ke-1

Lembar penilaian praktek pembelajaran, pada pertemuan kesatu rata-rata nilai praktek pembelajaran 94,8 kategori sangat baik, pertemuan kedua 96,9 dengan kategori sangat baik dan pertemuan ketiga 94,7 kategori sangat baik. Hasil skor rata-rata praktik pembelajaran JENG KELIN GALLAW Siklus ke-1 adalah 95,5 dengan kategori Sangat Baik.

Evaluasi praktek pembelajaran siklus-1 sebagai berikut.

a) Siswa dalam kolom learned masih sangat sederhana dalam menulis apa yang telah siswa dapatkan dalam tahap eksplorasi pertanyaan.

b) Siswa rupanya masih membuat catatan penting yang terjadi di luar tabel JENG KELIN, masih merasa ragu-ragu menulis apa yang telah siswa ketahui dalam kolom learned.

c) Pada tahap GALLAW siswa masih terlihat bingung dengan Gallery yang disajikan teman kelompok, karena tidak ada perwakilan kelompok pemilik gallery yang melakukan presentasi untuk menjelaskan sajian proyek siswa.

Refleksi Praktek Pembelajaran Siklus-1 sebagai berikut.

a) Peran guru adalah memberi siswa motivasi untuk percaya diri mengerjakan JENG KELIN, mengingatkan kembali fungsi dan peran JENG KELIN bagi siswa dan guru.

b) Pada pertemuan berikutnya guru sudah memmberitahu bahwa kolom learned dapat diisi langsung oleh siswa pada saat siswa melakukan eksplorasi tanpa diminta oleh guru.

c) Perlu adanya strategi presentasi oleh kelompok, sehingga pengunjung lebiih memahami apa yang disajikan oleh sebuah kelompok pada gallery yang dibuat oleh siswa. 
d) Strategi pemencaran anggota kelompok dipilih guru dengan pertimbangan setiap anggota kelompok mendapatkan hak yang sama dalam mempresentasikan hasil dan mendapat hak yang sama untuk ikut melakukan tahap walk.

\section{Hasil Siklus II}

Tes tulis literasi IPA kelas VIII-A dengan 3 indikator Literasi IPA pada PISA 2015. Hasil yang diperoleh berdasarkan analisis tes tulis Literasi IPA di kelas VIII-A sebagai berikut.

1. Indikator pertama: menjelaskan fenomena ilmiah dengan ratarata nilai 93,9.

2. Indikator kedua: merancang dan mengevaluasi penelitian ilmiah rata-rata nilai 85,0.Indikator ketiga: indikator menginterpretasi data dan bukti ilmiah rata nilai 96,1.

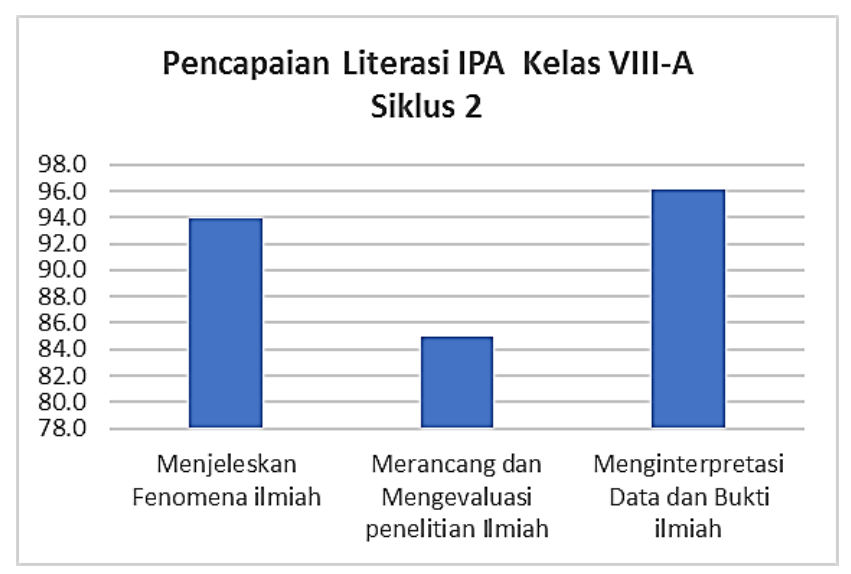

Gambar 2. Pencapaian Literasi IPA Siklus 2

Lembar penilaian praktek pembelajaran, pada pertemuan kesatu rata-rata nilai praktek pembelajaran 94,8 kategori sangat baik, pertemuan kedua 95,9 dengan kategori sangat baik dan pertemuan ketiga 97,9 dengan kategori sangat baik. Hasil skor rata-rata praktik pembelajaran JENG KELIN GALLAW Siklus ke-2 adalah 96,2 dengan kategori Sangat Baik.

Pemencaran anggota kelompok membuat siswa menjadi bersemangat menyiapkan diri dalam melakukan presentasi bersama kelompok.Pada pertemuan pertama banyak siswa yang masih bingung melakukan praktek pembiasan dengan plan parallel, karena instruksi dari guru kurang jelas bagi siswa yang berada di posisi belakang karena pada saat pelaksanaan Siklus ke-2 ada siswa kelas lain melakukan praktek penilaian tari di luar lab sehingga siswa kurang bagian belakang kurang 
mendengar instruksi guru, hal ini dapat diatasi guru dengan kemudian meminta siswa membaca kembali instruksi sendiri kembali beberapa waktu.

Refleksi hasil strategi pemencaran anggota pada Siklus ke-2 membuat siswa menjadi lebih bersemangat dalam melakukan $G A L L A W$, tahap ini masuk kedalam bagian dari tahapan pelaksanaan GALLAW yaitu pada sintaks ke-5 pelaksanaan GALLAW.

Siswa diberi angket respon pada pertemuan ketiga siklus kedua untuk mengetahui tanggapan atau respon siswa terhadap kegiatan pembelajaran JENGKELIN GALLAW pada pembelajaran IPA topik sifat cahaya, cermin dan lensa. Data hasil respon siswa yang terdiri dari 15 pertanyaan dikelompok menjadi 4 jenis pertanyaan, yaitu A) seputar minat, ketertarikan dan motivasi belajar; B) Keterlibatan dan kerjasama dalam kelompok; C) prestasi belajar IPA, D) Media refleksi. Berikut gambar respon siswa berdasarkan angket pembelajaran siklus kedua:

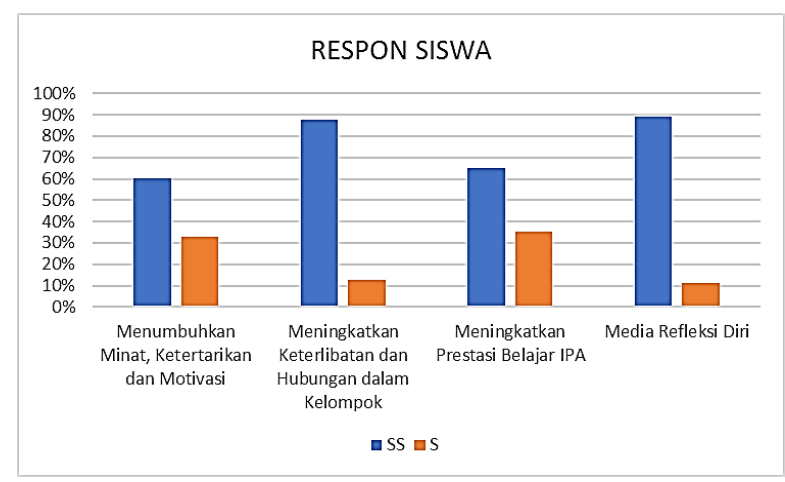

Gambar 3. Hasil respon siswa penerapan Model JENGKELIN GALLAW

Berdasarkan pelaksanaan Siklus ke-1 dan 2 dalam Penelitian Tindakan Kelas di kelas VIII-A, maka tampak sebagai berikkut.

1. Hasil tes literasi IPA silus 1 pada Siswa kelas VIII-A tuntas secara kalsikal dengan rata-rata 82,8 dan ketuntasan $89 \%$, hanya saja pada kompetensi literasi IPA yang kedua yaitu merancang dan mengevaluasi penelitian ilmiah rata-rata kelas masih dibawah yaitu 78,6. Nilai terendah pada mengevaluasi penelitian ilmiah yaitu dengan rata-rata 72,8 . sedangkan pada indikator merancang penelitian masih lebih tinggi yaitu rata-rata 84,4 .

2. Adanya peningkatan hasil tes literasi IPA pada Siklus ke-2 dengan rata-rata 90,0 dengan ketuntasan belajar 100\% dan nilai ketiga indikator literasi IPA mengalami 
peningkatan yaitu pada menjelaskan fenomena ilmiah, indikator menginterpretasi data dan bukti ilmiah serta indikator pada Siklus ke-1 yang dibawah KKM meningkat rata-ratanya menjadi 85,0 dengan merancang penelitian ilmiah $(83,9)$ dan Mengevaluasi penelitian ilmiah yaitu $(86,1)$.

3. Adanya peningkatan pada aspek keterampilan proses dari Siklus 1 ke Siklus 2.

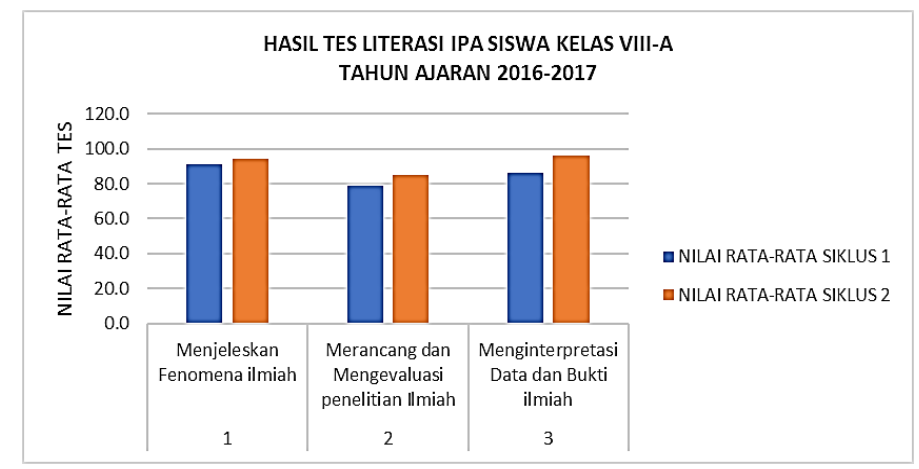

Gambar 4. Peningkatan Hasil Tes Literasi IPA

Berdasarkan data hasil belajar tersebut dapat dijelaskan bahwa pada Siklus ke-1 dan Siklus ke-2 hasil belajar IPA terutama dalam hal ini fokus pada kemampuan Literasi IPA siswa menagalami peningkatan. Hal ini menunjukkan bahwa inovasi model pembelajaran JENG KELIN GALLAW mampu mengatasi masalah yang dihadapi siswa di kelas VIII-A SMP Negeri 3 Jember pada topik sifat cahaya, cermin dan lensa dalam tujuan meningkatkan kemampuan literasi IPA. Grafik rata-rata hasil belajar siswa Siklus ke-1 dan Siklus ke-2 berdasarkan hasil tes literasi IPA siswa.

Keberhasilan hasil tes literasi IPA kelas VIII-A yang telah meningkat, setiap aktivitas belajar yang siswa lakukan dalam kelas menjadi perhatian siswa karena siswa harus menuliskan apa yang telah siswa pahami dalam pembelajaran IPA saat itu dalam jurnal belajar JENG KELIN. Siswa melakukan semua aktivitas tersebut secara aktif sebagai kesadaran diri untuk terus meningkatkan kompetensi dirinya sebagai bagian dari kelompok dalam penyelesaian proyek GALLAW. Sesuai dengan yang dituliskan oleh Al-Rawahi (2015-377) bahwa jurnal belajar reflektif mampu meningkatkan regulasi diri siswa, meningktakan respon siswa terhadap aktivitas pembelajaran dan instruksi guru, mellibatkan siswa lebih banyak lagi dalam pembelajaran. Penulisan JENG KELIN sangat membantu guru dalam memantau aktivitas dan pemahaman siswa, melatih keterampilan berpikir dan memberikan guru kemudahan melaakukan refleksi pembelajaran dan dengan segera memberikan tanggapan atas respon siswa terhadap 
pembelajaran saat itu, sehingga setiap kendala yang dihadapi siswa atau kesalahan konsep yang ada memudahkan guru untuk segera mendeteksi dan mengatasinya. Sesuai dengan kesimpulan dari Munawaroh (2015) tentang pengaruh penggunaan jurnal belajar sebagai refleksi belajar siswa dalam peningkatan kemampuan berpikir kritis.

Susunan kolom KELIN sebagai bentuk startegi pemrosesan informasi, memberikan siswa kemudahan dalam mengkonstruksi pengetahuan, menemukan hubungan antara apa yang telah siswa ketahui, ingin ketahui, siswa pahami dan mengaitkannya dengan contoh-contoh penerapan dan fenoma ilmiah yang ada dalam kehidupan sehari-hari. Sesuai dengan apa yang ditulis leh Campbell (2008:9) bahwa guru sebagai pendidik harus mampu mengaktifkan pengetahuan awal siswa nya dan mengetahui seberapa banyak perkembangan yang dicapai siswa dalam mengkonstruksi pengetahuan yang baru. Campbel (2008:11) juga menuliskan bahwa menghubungkan kenyataan dalam kehidupan sehari-hari dengan topik pembelajaran di kelas dan pengetahuannya akan memberikan siswa pengalaman bermakna sehingga pengetahuan tersebut akan lebih bertahan lama utuk diingat.

Pelaksanaan GALLAW, berdasarkan hasil observasi dan respon siswa menunjukkan hasil bahwa siswa semakin terampil dalam bekerjasama, berkolaborasi dan meningkatkan kepercayaan diri siswa dalam melakukan komunikasi sebagai individu dalam kelompok dan sebagai anggota kelompok dalam presentasi hasil. Sesuai dengan pernyataan Susilowati (2013) bahwa pembelajaran dengan basis proyek meningkatkan ativitas dan keterampilan siswa dan memberikan pengaruh positif pada hasil belajar.

\section{KESIMPULAN DAN SARAN}

Pelaksanaan Penelitian Tindakan Kelas dengan menggunakan model proyek JENG KELIN GALLAW disimpulkan dapat mengatasi permasalahan dalam upaya meningkatkan kemampuan literasi IPA di kelas VIII-A tahun ajaran 2017-2018 pada aspek kompetensi yaitu menjelaskan fenomena ilmiah, merancang dan mengevaluasi penelitian ilmiah, menginterpretasi data dan bukti ilmiah.

Hasil penelitian menunjukkan ada peningkatan kemampuan literasi IPA pada tiga indikator aspek komptensi 1) kemampuan menjelaskan fenomena ilmiah dari ratarata dari 91,1 naik menjadi 93,9 di siklus II, 2) merancang penelitian ilmiah dan 
evaluasi rata-rata dari 8,6 naik menjadi 85,0 pada siklus II; dan 3) mengintepretasi data dan bukti ilmiah rata-rata dari 86,1 naik menjadi 96,1 di siklus II. Hasil ini menunjukkan bahwa inovasi model pembelajaran JENG KELIN GALLAW dapat meningkatkan kemampuan literasi IPA siswa kelas VIII-A.

\section{DAFTAR PUSTAKA}

Al-Rawahi, N.M., \& Al-Balushi, S.M. 2015. The Effect of Reflective Science Journal Writing on Students' self - Regulated Learning strategies. International Journal of Environmental \& Science Education. 10(3): 367-379

Arif, M. 2013. Efektivitas Penerapan Metode Gallery Walk (Pameran Berjalan) Terhadap Hasil Belajar Siswa Pada Mata Pelajaran Pendidikan Agama Islam. EJournal Universitas Negeri Yogyakarta. (Online). (http://journal.student.uny.ac.id/jurnal/artikel/3985/93/429)

Campbell, L. M., Campbell, B. 2008. Mindful Learning: 101 Proven Strategies for Student and Teacher Success. second edition. USA, Corwin Press. Diakses melalui https://www.corwin.com//25914_081222_Campbell_Ch1_excerpt.pdf

Davis, P et al. 2015. Enhancing Metacognitive Literacy: A Research Study Using Sticky Notes in the Classroom. American International Journal of Contemporary Research. Vol. 5, No. 4; August 2015. www.aijcrnet.com, journals , Vol_5_No_4_August_2015>1.pdf.

Gusliani, G. 2014. Strategi inquiry menggunakan reading infusion dan science reflective journal writing kaitannya dengan literasi sains dan kemampuan kognitif siswa. (Online).(www.repository.upi.edu/12138/2/T_FIS_1202040_Abstract.pdf)

Iwamoto, D.H., Hargis, J., Hargis, J., \& Vuong. K. (2014). The effects of Project Based Learning on Students Performance. International Journal for the Scholarship of Technology Enhanced Learning. 1(1), 24-42.

Kemendikbud. 2016. Desain Induk Gerakan Literasi Sekolah. Dirjend dikdas dan menengah. Jakarta. (Online). (http://dikdas.kemdikbud.go.id/desain-induk-glskemendikbud/)

Munawaroh, L., Pantiwati, Y., Rofieq, A. 2015. Penggunaan Jurnal Belajar dalam Pembelajaran Class Wide Peer Tutorial terhadap kemampuan berpikir kritis siswa. Jurnal Pendidikan Biologi Indonesia (ISSN:2442-3750) 
OECD. 2016. Country Note Programme for International Student Assessment (PISA) result from PISA 2015. (online) https://www.oecd.org/PISA/PISA2015Indonesia.pdf

OECD. 2016. Country note: Result from PISA 2015. (Online). (https://www.oecd.org/pisa/PISA-2015-Indonesia.pdf).

P21 (Partnership for 21st Century Skills). 2011. Framework for 21st Century Learning. (Online). (www.p21.org/storage/documents/1._p21_farmework_2-pager.pdf)

Prasetiyaningsih, A. 2014. Peningkatan hasil belajar siswa dengan strategi Gallery Walk materi Sistem Pencernaan makanan siswa SMPN 3 Jember kelas VIII-F tahun ajaran 2014-2015. PTK guru, tidak diterbitkan, Perpustakaan SMP 3 Jember.

Sani, R.A. 2013. Inovasi Pembelajaran. Bumi Aksara. Jakarta

Sumarni, W. 2013. The Strengths and weaknesses of the implementation of Project based learning. International Journal of Science and Research (IJSR). 4(3), 478484.

Susilowati, I., Iswari, R., Sukaesih, S. 2013. Pengaruh pembelajaran berbasis proyek terhadap hasil belajar siswa materu sistem pencernaan manusia. Unnes Journal Biology Education. 2(1):82-90.

Towndrow, P.A., Ling, T.A., Venthan, A.M. 2008. Promoting Inquiry Through Science Reflective Journal. Eurasia Journal of Mathematics, Science \& Technology Education. 4(3):279-283. (online). (www.elainegalvin.ie)

Velazquez, C.R., Martinez, L.C., \& Visscher, P.T. 2007. Learning Geomicrobiology as a Team Using Microbial Mats, a Multidisciplinary Approach. Journal of Microbiology\&Biology

Education.8(1):28-

5.(Online).(www.physics.emory.edu.pdf.)

Wati, A., \& Susilo, H. 2016. Implementasi Jurnal Belajar dalam pembelajaran sains. Pros. Semnas Pend. IPA Pascasarjana Universitas Negeri Malang. Vol 1:856864.

Zouhor, Z., Bogdanovic, Segedinac, M. 2016. Effects of the Know-Want-Learn Strategy on primary school students's metacognition and physics achievement. Journal of Subject Didactics vol.1 (1), 39-49. 